\title{
The Economic Analysis of Crime Behavior-Deduction of the Game Model between the Law-Man and the Offender
}

\author{
Shanshan Pan \\ School of Government, Beijing Normal University, Beijing, China \\ Email:panshan_164@163.com
}

Received 28 June 2016; accepted 15 July 2016; published 18 July 2016

Copyright @ 2016 by author and Scientific Research Publishing Inc.

This work is licensed under the Creative Commons Attribution International License (CC BY). http://creativecommons.org/licenses/by/4.0/

(c) (i) Open Access

\begin{abstract}
George Tsebelis (1989) first uses the game model to analyze the behavior of police and public, but he has been questioned by many scholars in the related research. George' conclusion and the scholars' opinions are based on the premise that no pure strategy Nash equilibrium exists in the game. In fact, pure strategy Nash equilibrium exists in certain conditions, and it is necessary to study it because of the stabilization. In this paper, we research on the interaction of the law-man and the offender, and study how the law-man type and the conviction rate influence the behavior of the game participants. This paper also tests the conclusion of George, in the 1V1 game with the $100 \%$ conviction rate, the conclusion is correct that the increase of punishment can't reduce the crime. This paper further discusses the law enforcement range that the law-man can be competent, and how the law-man type, law enforcement costs and the number of law-men impact the law enforcement range.
\end{abstract}

\section{Keywords}

Law-Man, Offender, Game, The Law-Man Type, Conviction Rate

\section{Introduction}

The research attempts to analyze the interaction process between the law-man and the offender by game theory, so as to find out the various variables that control the behavior of the crime. The classic literature on this topic can be traced back to Becker (1968) [1] who used economic methods to analyze the relationship between crime and punishment. After Becker, many scholars had studied how to prevent and reduce the crime from different angles, including the economic and the social perspective. 
George Tsebelis (1989) [2] proposed the existence of Crusoe fallacy, he was the first one who used game theory to study crime, and he thought it was not suitable for the use of decision theory to study the condition that another participant was individual rationality, rather than nature. George gave two examples to distinguish game theory and decision theory. The problem whether people should stay at home or go out when it was likely to rain need to be solved by decision theory, because the other participant was nature and whether it would rain or not was independent of the people's strategy, while the problem whether people should break or obey the traffic regulation when the police may enforcement need to be solved by game theory, because the other participant was the police who was rationality and would adjust his strategy according to the people's. Based on the above description, George put forward using the game theory rather than decision theory to study the crime, otherwise it would produce a Robinson Crusoe fallacy. It is worth mentioning that, in the case that George used game theory to analyze the violation of traffic rules, it was concluded that the fine was not related to the probability of the crime.

George Tsebelis (1989) [3] then analyzed the relationship between the crime and the punishment, and he used the algebraic expression obtained from the study of the mixed game Nash equilibrium to prove that punishment had nothing to do with the probability of crime which was contrary to the intuition. This conclusion has been questioned and supported by many scholars. William Bianco and Peter Ordeshook (1990) [4] questioned George of the one-time game premise and the technical error in the parsing process. George replied their query, and proved the robustness of the conclusions. Weissing and Ostrom (1991) [5] considered that there was premises of the conclusion which only held in the case that the law-men and the offenders in the two groups have no individual differences. Hirshleifer and Rasmusen (1992) [6] questioned the assumptions in George's model that the two participants made the decision simultaneously and the participants focused on two alternative strategies. George Tsebelis (1993) [7] replied the questions of Weissing and Ostrom (1991) [5], as well as Hirshleifer and Rasmusen (1992) [6] respectively in two angles of theory and experience. Even though some scholars kept their opinions on his conclusion, George believed that they basically agreed on two points: 1) Crusoe fallacy existed, and the research on the interaction of the police and the public should use game theory; 2) Improving punishment would reduce the probability of the illegal activities. Gary Cox (1994) [8] believed that George's conclusion was correct on his premises and assumptions, but his game theory model did not fully explain the actual problem, and he proposed the alternative model, which proved that increasing the fine can reduce the law enforcement probability, but the reduction could not completely offset the full impact of the fine on the probability of illegal. Some scholars had done the model extension based on George's research, Luciano Andreozzi (2004) [9] held that George's conclusion from the mixed strategy equilibrium was not stable, the game problem should be solved by minimax strategy, first mover advantage was set up in the game, and the police become Stackelberg leader. Luciano used the static comparative analysis to prove that increasing punishment would reduce the probability of law enforcement, but also reduce the crime, and increasing incentives of the police would reduce the probability of law enforcement and increase the probability of illegal crime.

Luciano Andreozzi was not the first scholar to propose that to incentive the police can not deter the criminal act, which was the conclusion inconsistent with the intuition in Sugata Marjit and Heling Shi [1998]'s study [10]. Sugata and Heling introduced the corruption factor into the crime analysis process by the strategy theory. It is proved that when the offender in the arrest can bribe the police, as long as the police can control the probability of detection, even if introduce the incentive plan, crime still can not be eliminated. It is worth mentioning that Sugata and Heling did not introduce a third party involved in the supervision of the police in the setting of corruption and law enforcement model, and corruption and punishment take place only among the police and the public. The model is still based on the game between the police and the public, and corruption factors are included in the parameter of the law-man type $\theta$.

Franklin Allen, Jun Qian and Lin Shen (2015) [11] considered it was a limit to alleviate the agency problem through the performance salary, restricting corruption by law was frequently unsuccessful, and the study suggested to introduce competition mechanism among the official to limit corruption, which meant that the effect of corruption would be minimum and the central government would reduce the optimal payment through different officials providing the same public products and services.

Up to now, the study of the crime by game theory is based on the mixed strategy Nash equilibrium, and almost all scholars believe that the game between the police and the public has no pure strategy Nash equilibrium. However, it is well known that mixed strategy Nash equilibrium in each round of the game strategy is unstable, so the random reduces its practical significance. We discuss the game between the law-man and the offender 
which exist the pure strategy Nash equilibrium, the second part builds the game model, which starts from the simplest condition to the gradually more complex conditions. We try to take the reality of law enforcement in the game model and so as to discuss the various problems in the actual enforcement. The third part is the conclusion.

\section{Game Model}

This research takes the hamster game as an example to firstly establish the simplest situation model: a man (law enforcement, named law-man) who holds a wooden stick (to combat illegal ways) guards a bunch of corn (public property). A group of hamsters (offenders) steal the corn. Each hamster acts alone, and it will injured and unable to get the corn, if it is found and beaten by the law-man, if not, the hamster will get the corn, then the corn guarded by the law-man reduces by one unit.

Firstly, to explore the simplest case, that is, a law-man against a hamster. Assuming the utility of each corn (value of public goods) is $\mathrm{H}$, which is also the corn's utility to the hamster. The law-man strike the hamster once cost $b$. The hamster will pay a damage $h$ if it is beaten once. Assuming that each corn's utility is less than $H$ to the law-man, and it worth differently to different law-men. Assuming the law-man type is $\theta(0<\theta<1)$, then the utility of the corn is $\theta \mathrm{H}$ to the law-man. $\theta$ is different according to the different social, cultural values, and different law-men.

1) First case: One law-man against one offender when conviction rate is $100 \%$

The complete information static game model is shown in Figure 1.

In Figure 1, if $\mathrm{H}<\mathrm{b} /(2 \theta)$, which is obviously stable and has nothing to do with $\mathrm{h}$, there will be one and the only pure strategy Nash equilibrium (do not hit, take corn). That means, to increase the punishment can not reduce the crime, which is consistent with George's conclusion [3]. Consequently, when the law-man type $\theta$ and b are fixed, the smaller the utility of public property is, and the more easily the law-man is to ignore the crime and let the hamster steal the corn. Therefore, under the premise that there are no other factors, when the total of the utility of the property is smaller to certain "boundary" $(\mathrm{b} /(2 \theta))$, the attitude of the law-man to the offender is stable to take the "do not hit" strategy. Maybe the victim lost a bike then the law-man was not to act, and may also be the victim lost a car then the law-man was not to act. However, no matter what kind of situation, the law-man encouraged certain amount of crime.

In addition, the size of the illegal "boundary" value $(\mathrm{b} /(2 \theta))$ is particularly important, as you can imagine in a society, when the illegal "boundary" value is very high, the law-man is almost useless and people practically have no personal property rights. The type of law-man is one of the decisive factors of the illegal boundary. If the degree of the combination $(\theta)$ of law-man's own interests and public interests increases, namely the social reward of fight against crime increases, criminal resistance ability decreases, the bribery probability decreases, or the social tolerance degree of the deteriorating security situation decreases, the "boundary" value will decrease, then the proportion of the law-man who ignore the crime will decrease, and the existence range of pure strategy Nash equilibrium (do not hit, take corn) will decrease. In this case, the incentive of the law-man to combat crime is higher, and the probability of adopting a stable strategy "do not hit" is smaller.

2) Second case: One law-man against one offender when conviction rate is $p$

In the whole process of the law enforcement, the role of the court is very important. The supervisor thought

hamster

\begin{tabular}{|c|c|c|}
\hline & take corn & do not take corn \\
\hline law-man hit & $(\theta \mathrm{H}-\mathrm{b},-\mathrm{h})$ & $(-b, 0)$ \\
\hline do not hit & $(-\theta H, H)$ & $(0,0)$ \\
\hline
\end{tabular}

Figure 1. The payment function of one law-man against one offender when conviction rate is $100 \%$. 
the offender was guilty, but he maybe released during the enforcement of the court. If the probability of such an innocent release is large, it will in turn affect the law-man type, so it is necessary to introduce the conviction rate of this variable in the game model.

In the hamster model of game, not all law-man can hit the hamster accurately, because the hamster maybe very clever to escape the attack or the law-man makes mistakes when striking. Assuming the probability that the law-man hits the hamster correctly is p. The game model is shown in Figure 2.

To discuss the pure strategy Nash equilibrium in Figure 2: If $\mathrm{H}<\mathrm{b} /(\mathrm{p}+\mathrm{p} \theta-1+\theta)$, which is obviously stable and has nothing to do with h, there will be only one pure strategy Nash equilibrium (do not hit, take corn). That means, to increase the punishment can not reduce the crime, which is consistent with George's conclusion [3]. Because $\mathrm{b} /(\mathrm{p}+\mathrm{p} \theta-1+\theta)>\mathrm{b} /(2 \theta)$, and $\mathrm{b} /(\mathrm{p}+\mathrm{p} \theta-1+\theta)$ will increase if $\mathrm{p}$ decreases, the range that the law-man ignores the crime of the hamster will increase, if the conviction rate $\mathrm{p}$ reduces and the other conditions remain unchanged.

If $\mathrm{H}>\mathrm{b} /(\mathrm{p}+\mathrm{p} \theta-1+\theta)$ and $\mathrm{H}>(\mathrm{ph}) /(1-\mathrm{p})$, there will be only one pure strategy Nash equilibrium (hit, take corn). When $\mathrm{b} /(\mathrm{p}+\mathrm{p} \theta-1+\theta)>(\mathrm{ph}) /(1-\mathrm{p})$, that is $\mathrm{h}<\beta \mathrm{b}, \beta=(1-\mathrm{p}) /[\mathrm{p}(\mathrm{p}+\mathrm{p} \theta+\theta-1)]$, in the entire $\mathrm{H}$ range except $\mathrm{H}=\mathrm{b} /(\mathrm{p}+\mathrm{p} \theta-1+\theta)$, there is only one pure strategy Nash equilibrium which is either (hit, take corn) or (do not hit, take corn).In this set of circumstances, the hamster is always take the strategy "take corn" Conversely, when the amount of punishment is greater than $\beta$ b, the hamster's strategy will change, and it no longer takes corn with one hundred percent of the probability, so to deter the crime on certain degree, which is not consistent with George's conclusion [3]. Whether or not to protect corn is entirely determined by law-man type and conviction rate when $\mathrm{b}$ and $\mathrm{h}$ are constant. The premise that the hamster always takes the strategy "take corn" is $\mathrm{h}<\beta \mathrm{b}$, that means the hamster is hit by the damage value which is smaller than the $\beta$ times of the cost of hit. At this time, because the hit intensity is too small, even if the law-man is willing to hit, the hamster will take the risk of injury to get the corn.

Public property protect rely on the strength and the breadth of the law-man against crime. Although the ideal condition (do not hit, do not take corn) can enable minimizing the enforcement cost and the public loss, it is impossible to become an equilibrium. The offender will choose crime, if punishment is not enough, because crime creates possible profit. Conviction rate p provides offenders profit by possible escape from the law then motivates the offender to violate the law.

In addition, the law-man type $\theta$ is a key variables. If $\mathrm{H}<\mathrm{b} /(\mathrm{p}+\mathrm{p} \theta-1+\theta)$, and $\theta$ increases, $\mathrm{b} /(\mathrm{p}+\mathrm{p} \theta-1+\theta)$ will reduce. That is, when the other conditions remain unchanged, if the degree of the combination $(\theta)$ of lawman's own interests and public interests increases, namely the social reward of fight against crime increases, criminal resistance ability decreases, the bribery probability decreases, or the social tolerance degree of the security situation deteriorated decreases, the percentage of the law-man who ignore the crime will decrease.

The two conditions discussed above are between one law-man and one offender, and the types of the law-man and conviction rate play crucial roles in deterring the crime. In the society where the law-men combine their own interests and the public interests better the law-man is less possible to keep a blind eye to illegal activities, and punishment system can be better implemented. Increasing the conviction rate can also stimulate law-man to against illegal behavior, then the punishment system can be better implemented too.

3) Third case: One law-man against several offenders

In reality, a law-man does not confront one offense. When the offender is large in number, is law-man

hamster

\begin{tabular}{l|c|c|}
\multicolumn{1}{c}{ take corn } & \multicolumn{2}{c|}{ do not take corn } \\
\cline { 3 - 4 } law-man & $((1+\theta) \mathrm{pH}-\mathrm{b}-\mathrm{H}, \mathrm{H}(1-\mathrm{p})-\mathrm{ph})$ & $(-\mathrm{b}, 0)$ \\
\cline { 3 - 4 } do not hit & $(-\theta \mathrm{H}, \mathrm{H})$ & $(0,0)$ \\
\hline
\end{tabular}

Figure 2. The payment function of one law-man against one offender when conviction rate is $\mathrm{p}$. 
competent? How many offenders can a law-man can manage? In other words, what is the scope of law enforcement for a law-man?

Assume the number of the hamster is $\mathrm{x}$. The best choice for the hamsters is to steal the corn at the same time, so the conviction rate is supposed $\mathrm{p}=1 / \mathrm{x}$. This assumption may be questioned, because in reality all offenders may not prior to discuss to breaking the law at the same time, then $\mathrm{x}$ can be viewed as the expectation of the number of illegal activities, which is still a measure of the size of the offenders. The game model is shown in Figure 3.

The game model in Figure 3 still exists pure strategy Nash equilibrium. When $1+\mathrm{h} / \mathrm{H}<\mathrm{x}<(1+\theta) \mathrm{H} /(\mathrm{b}+\mathrm{H}$ $-\theta \mathrm{H}$ ), the only one pure strategy Nash equilibrium is (hit, take corn).If $\mathrm{h}$ increases, $1+\mathrm{h} / \mathrm{H}$ will increase, the existence range of pure strategy Nash equilibrium will reduce, and the mixed equilibrium will emerge, which means the probability that offenders take the corn will be less than $100 \%$. In this case, illegal behavior is constrained, which is not consistent with George's conclusion [3]. If $\mathrm{x}>(1+\theta) \mathrm{H} /(\mathrm{b}+\mathrm{H}-\theta \mathrm{H})$, the only one pure strategy Nash equilibrium will be (do not hit, take corn). At this point, the critical value of $\mathrm{x}$ was found $\mathrm{x}^{\prime}(\theta, \mathrm{b})=$ $(1+\theta) \mathrm{H} /(\mathrm{b}+\mathrm{H}-\theta \mathrm{H})$. Once the $\mathrm{x}$ exceeds $\mathrm{x}$ ', the pure strategy Nash equilibrium will jump from (hit, take corn) to (not hit, take corn). The attitude of the law-man to the offense is from the fight against the crime to ignore the crime. This value can be considered as the law enforcement limit. So x' is the law enforcement scope limit, which means a law-man can manage $\mathrm{x}$ ' offenders at most.

$\mathrm{x}^{\prime}$ is the function of $\theta$ and $\mathrm{b}$, where $\theta$ is still the key variables. If $\theta$ increases, $\mathrm{x}^{\prime}$ will increase. That is, when the other conditions remain unchanged, the higher combination $(\theta)$ of law-man's own interests and public interests is, namely the social reward of fight against crime increases, criminal resistance ability decreases, the bribery probability decreases, or the social tolerance degree of the security situation deteriorated decreases, the more law enforcement limit is. $\mathrm{b}$ is another important parameter. When the other conditions remain unchanged, If $\mathrm{b}$ increases, $\mathrm{x}^{\prime}$ will decrease, then the range of the law enforcement limit will decrease. When $\theta=1, \mathrm{x}^{\prime}=2 \mathrm{H} / \mathrm{b}$, the law enforcement limit is maximum because of the maximum $\theta$. In this case, the law enforcement limit depends on the gap between $\mathrm{H}$ and $\mathrm{b}$. If $\mathrm{b}$ is large enough to approach $\mathrm{H}$, the law-man who protects the public property as his own property can only guard the maximum number of 2 offenders.

4) Forth case: Several law-men against several offenders

On the basis of the game model above, consider the situation that the number of the law-man is greater than 1 . We assume that the number of the law-man is $\mathrm{y}$, and the number of the offender is still $\mathrm{x}, \mathrm{y}<\mathrm{x}$. As in the previous analysis, the conviction rate is $\mathrm{y} / \mathrm{x}$, and the game model is shown in Figure 4.

The game model in Figure 4 still exists pure strategy Nash equilibrium. When $\mathrm{y}(1+\mathrm{h} / \mathrm{H})<\mathrm{x}<(1+$ $\theta) \mathrm{yH} /(\mathrm{b}+\mathrm{H}-\theta \mathrm{H})$, the only one pure strategy Nash equilibrium is (hit, take corn). Similar to the last case, If $\mathrm{h}$ increases, the existence range of pure strategy Nash equilibrium will reduce, then the illegal behavior will be constrained to some degree, which is not consistent with George's conclusion [3].

Comparing with the third condition, the law enforcement limit changes from x' to yx', namely the game between y law-men and $\mathrm{x}$ offenders, and the upper law enforcement limit in this condition is y times as much as the law enforcement limit in the last condition. The upper law enforcement limit is proportional to the number of law-men.

We need to pay attention to the lower law enforcement limit. When $x<y(1+h / H)$, (hit, take the corn) is not a pure strategy Nash equilibrium. If the number of law-men approaches to the number of offenders, the conviction rate will greatly increase, so that a part of the offenders will give up the illegal behavior and choose to obey the law.

hamster

\begin{tabular}{c|c|c|}
\multicolumn{1}{c}{ take corn } & do not take corn \\
\cline { 2 - 3 } law-man hit & $((1+\theta) \mathrm{H} / \mathrm{x}-\mathrm{b}-\mathrm{H}, \mathrm{H}(1-1 / \mathrm{x})-\mathrm{h} / \mathrm{x})$ & $(-\mathrm{b}, 0)$ \\
\cline { 3 - 3 } do not hit & $(-\theta \mathrm{H}, \mathrm{H})$ & $(0,0)$ \\
\hline
\end{tabular}

Figure 3. The payment function of one law-man against several offenders. 
hamster

\begin{tabular}{|c|c|c|}
\hline & take corn & lot take c \\
\hline law-man hit & $((1+\theta) y H / x-b-H, H(1-y / x)-y / x)$ & $(-b, 0)$ \\
\hline do not hit & $(-\theta H, H)$ & $(0,0)$ \\
\hline
\end{tabular}

Figure 4. The payment function of several law-men against several offenders.

\section{Conclusions}

The game model in this paper makes some deductions about four steps based on the complexity, trying to make the model closer to the reality, and get some conclusions in every step.

From the first case, one law-man against one offender when conviction rate is $100 \%$, we find that if the total value of the public property is less than the boundary value, the law-man will ignore the illegal activities. The law-man type is one of the determinants of the boundary value, and the higher combination of law-man's own interests and public interests is, the more likely that the law-man ignore the illegal activities. In the second case, one law-man against one offender when conviction rate is $\mathrm{p}$, we found that under certain conditions, regardless of the law enforcement intensity of the law-man, the offender always chooses to break the law. The ideal state (do not hit, do not take corn) is difficult to reach, but the high conviction rate and the high value of the law-man type can motivate the law-man to fight against the crime and make the punishment system more effective. In the third case, one law-man against several offenders, we get the law enforcement limit, which is related to the law-man type and law enforcement costs. In the last case, several law-men against several offenders, we get the upper and lower law enforcement limit.

During the deduction, this paper tests George’s conclusion, which is correct only in case one.

\section{Fund}

This work was supported in part by the National Social Science Foundation of China (Grant No.13AZD093 and 15BGL154). The views expressed herein are those of the authors and are not necessarily those of the National Social Science Foundation of China.

\section{References}

[1] Becker, G.S. (1968) Crime and Punishment: An Economic Approach. Journal of Political Economy, 76, 169-217. http://dx.doi.org/10.1086/259394

[2] Tsebelis, G. (1989) The Abuse of Probability in Political Analysis: The Robinson Crusoe Fallacy. American Political Science Review, 83, 77-91. http://dx.doi.org/10.2307/1956435

[3] Tsebelis, G. (1989) Penalty Has No Impact on Crime: A Game Theoretic Analysis. Rationality and Society, 2, $255-286$. http://dx.doi.org/10.1177/1043463190002003002

[4] Bianco, W.T., Ordeshook, P.C. and Tsebelis, G. (1990) Crime and Punishment: Are One-Shot, Two-Person Games Enough? The American Political Science Review, 84, 569-586.

[5] Weissing, F. and Ostrom, E. (1991) Crime and Punishment: Further Reflections on the Counterintuitive Results of Mixed Strategy Equilibria Games. Journal of Theoretical Politics, 3, 343-350. http://dx.doi.org/10.1177/0951692891003003006

[6] Hirshleifer, J. and Rasmusen, E. (1992) Are Equilibrium Strategies Unaffected by Incentives? Journal of Theoretical Politics, 4, 353-367. http://dx.doi.org/10.1177/0951692892004003007

[7] Tsebelis, G. (1993) Penalty and Crime: Further Theoretical Considerations and Empirical Evidence. Journal of Theoretical Politics, 5, 349-374. http://dx.doi.org/10.1177/0951692893005003003

[8] Cox, G.W. (1994) A Note on Crime and Punishment. Public Choice, 78, 115-124.

http://dx.doi.org/10.1007/BF01053369 
[9] Andreozzi, L. (2004) Rewarding Policemen Increases Crime. Another Surprising Result from the Inspection Game. Public Choice, 121, 69-82. http://dx.doi.org/10.1007/s11127-004-6166-x

[10] Marjit, S. and Shi, H.L. (1998) Rewarding Policemen Increases Crime. Another Surprising Result from the Inspection Game. Public Choice, 121, 69-82.

[11] Allen, F., Qian, J. and Shen, L. (2007) Corruption and Competition. Social Science Electronic Publishing, Beijing.

\section{Submit or recommend next manuscript to SCIRP and we will provide best service for you:}

Accepting pre-submission inquiries through Email, Facebook, LinkedIn, Twitter, etc.

A wide selection of journals (inclusive of 9 subjects, more than 200 journals)

Providing 24-hour high-quality service

User-friendly online submission system

Fair and swift peer-review system

Efficient typesetting and proofreading procedure

Display of the result of downloads and visits, as well as the number of cited articles

Maximum dissemination of your research work

Submit your manuscript at: http://papersubmission.scirp.org/ 